\title{
EFFECT OF SHRINK WRAPPING ON SHELF LIFE OF BANANAS
}

\author{
D. SUREKHA ${ }^{1}$, T. SRAVAN ${ }^{2} \&$ L. EDUKONDALU ${ }^{3}$ \\ ${ }^{1,2}$ Department of Agricultural Engineering, Aditya Engineering College, Surampalem, India \\ ${ }^{3}$ Department of Agricultural Process and Food Engineering, College of Agricultural Engineering, Bapatla, India
}

\begin{abstract}
Mature green locally available bananas (Chakkerkeli) were pretreated (hot water $50{ }^{\circ} \mathrm{C} ; 10$ min) and shrink wrapped in shrink films of polyolefin $15 \mu$ and cryovac $9 \mu$ and stored at ambient storage conditions $\left(\right.$ Temp $=33^{\circ} \mathrm{C}$; $\mathrm{RH}$ $72 \%)$. An experiment was conducted, both for fingers and hands; periodical observation was recorded in $\%$ weight loss, firmness, colour, percent decay and the CO2 transmission rate of stored bananas. The PLW increased gradually in banana, during the storage period. Hands wrapped with polyolefin $15 \mu$, recorded the lowest weight loss of $1.72 \%$, followed by hands wrapped with cryovac $9 \mu$. Unwrapped fingers recorded more weight loss (27.48\%) compared with wrapped fingers by the end of storage period. The fruit firmness followed a declining trend because of the softening of fruit tissues. Hands wrapped in polyolefin $15 \mu$ recorded highest firmness $(3.65 \mathrm{~kg})$. The Colour of the fruits changed slowly from green to yellow. The highest colour change from green to yellow was recorded with unwrapped finger bananas and the lowest was observed with hands wrapped with polyolefin $15 \mu$. Decay percentage increased gradually, during the storage period. But, the rate of decay was faster in unwrapped treatments. The CO2 transmission rate increased, with the increase in storage period with lowest in hands, wrapped with polyolefin $15 \mu$. It was noticed that, shrink film increased the shelf life and maintained the quality of banana fruits for 14 days, under ambient conditions.

KEYWORDS: Chakkerkeli, Fingers, Hands, Physiological Parameters, Shrink Wrapping, Polyolefin $15 \mu$ \& Cryovac $9 \mu$
\end{abstract}

Received: Sep 21, 2017; Accepted: Oct 09, 2017; Published: Oct 28, 2017; Paper Id.: IJASRDEC201715

\section{INTRODUCTION}

Banana (Musa sp.) is a large perennial herb with leaf sheaths that form trunk like pseudo stem. Banana is a globally important fruit crop with 97.5 million tons of production. Banana is a rich source of carbohydrate and vitamins. Banana powder is being used as one of the ingredients of baby food.

Bananas are generally harvested early in the season at a pre-mature stage to capture early market. Fruit production has increased but the post-harvest losses are not controlled. In a tropical country like India, these losses occur due to various reasons like lack of proper storage facilities, improper handling during long distance transport and rapid ripening due to high temperature followed by microbial spoilage. Banana being a highly perishable fruit, shows high post-harvest losses to the extent of about 20-30\%, Sreenivasa et al. (2009).

The increased production of banana is supplemented with efforts to minimize post-harvest losses, by adopting a suitable technique with proper storage conditions. Shrink wrapping produces a micro atmosphere and retard ripening, by limiting the exchange of oxygen and carbon dioxide and can interplay with the physiological processes of commodity, resulting in reduced rate of respiration, transpiration and other metabolic processes of fruits, thereby allowing lower physiological weight loss, reducing decay incidence and maintaining retention of colour and texture of fruits, during extended shelf life, Sharma et al (2010). 


\section{MATERIALS AND METHODS}

Matured banana bunches (Variety: Chakkerkeli) were separated into banana fingers and hands, uniform sized fruits were selected. Diseased, bruised, ripened and cracked fruits were discarded. The fruits were cured with hot water $\left(50^{\circ} \mathrm{C}\right.$ for $\left.10 \mathrm{~min}\right)$ and then shade dried at room temperature, to remove adhered moisture. Cured fruits were shrink wrapped in different heat shrinkable films(Polyolefin $15 \mu$ and Cryovac $9 \mu$ ) and then stored under suitable storage conditions (Temp $=33^{\circ} \mathrm{C} ; \mathrm{RH} 72 \%$ ).

Data on weight loss, firmness, colour were recorded on alternate days, whereas, percent decay and the $\mathrm{CO} 2$ transmission rate were recorded at three-day interval of 15 days.

\section{Physiological Loss of Weight}

Physiological loss of weight for each treatment was calculated by the following formula.

$\% \mathrm{PLW}=\underline{\text { Initial weight- Final weight }} \times 100$

Initial weight

\section{Firmness}

Fruit firmness was evaluated twice on each fruit at alternate days using fruit firmness device (Wagner, model FT327).

\section{Measurement of Colour by Hunter Lab Colour Flex Meter}

The colour of banana samples was measured using Hunter lab colour flex meter (M/s. Hunter lab, Reston, VA, USA; model CFLX-45). The surface colour was quantified in terms of $\mathrm{L}^{*}, \mathrm{a}^{*}$ and $\mathrm{b}^{*}$ values of CIELAB colour space. Colour index $(C I)$ of the sample was measured by measuring $\mathrm{L}^{*}, \mathrm{a}^{*}$ and $\mathrm{b}^{*}$ values and was calculated, using the following equation as suggested, by Soltani et al. (2011b).

Colour index $=1000 \mathrm{a}^{*} / \mathrm{L}^{*} \mathrm{~b}^{*}$

\section{Decay (\%)}

Percentage decay was determined as percentage of infected banana fruit in relation to the total number of fruits and was calculated using equation given, by Embaby et al. (2013).

Decay $(\%)=\underline{\text { Numberofdecayfruits }} \times 100$

Total number of testing fruits

\section{$\mathrm{CO}_{2}$ Transmission Rate}

The CO2transmission rate in the packed samples was evaluated at regular intervals, using a head space gas analyzer (PBI Dan sensor, model Checkmate II).

\section{Statistical Analysis}

The experiment was laid out in the Complete Randomized Design (CRD) and the data gathered were statistically analyzed using WASP (web agriculture statistical package). 


\section{RESULTS AND DISCUSSIONS}

Physiological loss of weight of Chakkerkeli bananas wrapped in different heat shrinkable films increased with the increase in storage period (Figure.1). Hands wrapped with polyolefin $15 \mu$ significantly recorded the lowest loss of weight. Unwrapped fingers recorded the highest loss of weight during the storage period. The moisture loss rate was faster in control, compared to the shrink wrapped samples. Reduction in PLW may be primarily due to the reason that the material acts as a barrier to moisture loss and also creates high relative humidity around the fruit thereby retarding the moisture loss during storage. Similar results were reported by Rashid et al. (2012) in 'milk' banana.

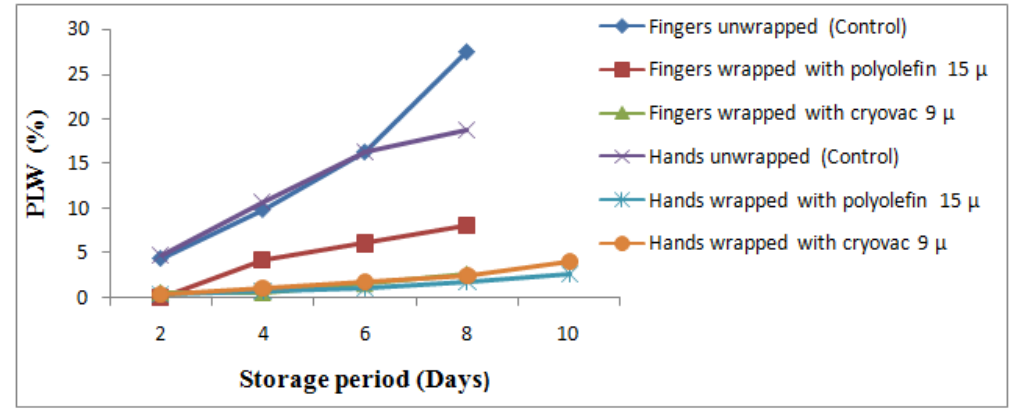

Figure 1: Effect of Heat Shrinkable Films on PLW (\%) of Chakkerkeli Bananas

A gradual decline in firmness in film packed fruits was noticeable with advancement of storage period, whereas in control package the decline in fruit firmness was found to be abrupt and fast (Figure.2). Chakkerkeli hands wrapped with polyolefin had higher firmness. The decrease in firmness in all the treatments was caused by softening of the fruit, due to conversion of insoluble proto pectin into soluble pectin. Also, when the fruit started ripening as a result of which, cell wall integration is distributed, which lowered down the fruit texture during the storage. A similar trend was observed by Tapre et al. (2012) in 'Robusta' banana.

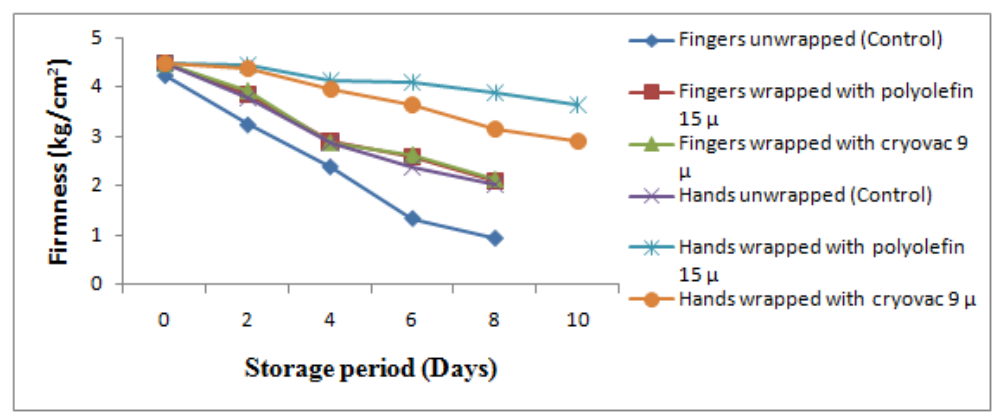

Figure 2: Effect of Heat Shrinkable Films on Firmness of Chakkerkeli Bananas

The shrink wrapped bananas showed a gradual colour change from green to yellow (Figure.3). The colour change in unwrapped treatments is more rapid than the wrapped treatments. The results revealed that, polyolefin $15 \mu$ had delayed colour changes and slowed down yellowing of the banana. Colour-break is the visual manifestation of the fruit ripening where peel colour changes from green to golden yellow, which is mainly attributed due to breakdown of chlorophyll pigments in the peel tissue. 


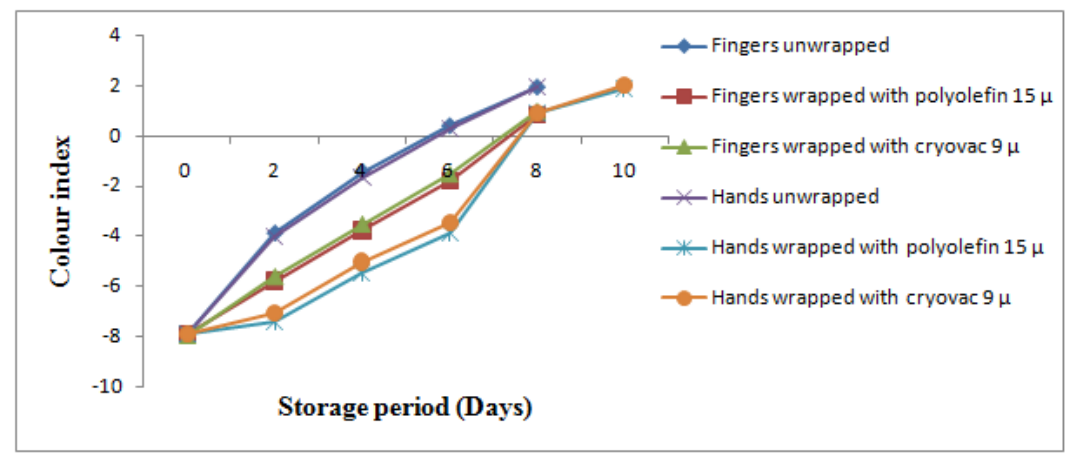

Figure 3: Effect of Heat Shrinkable Films on Colour Index of Chakkerkeli Bananas

Decay percentage of Chakkerkeli bananas increased with increase of storage period. But, the rate of decay was slow in shrink wrapped treatments (Figure.4). Chakkerkeli hands wrapped with cryovac $9 \mu$ recorded the highest decay of $45.71 \%$ and the lowest $31.4 \%$ was recorded, with polyolefin $15 \mu$ wrapped hands. Increase in the decay of fruits was attributed due to rapid senescence, followed by fungal development on the surface of fruits. Similar results were observed by Nazmy et al. (2012), in pomegranate fruits.

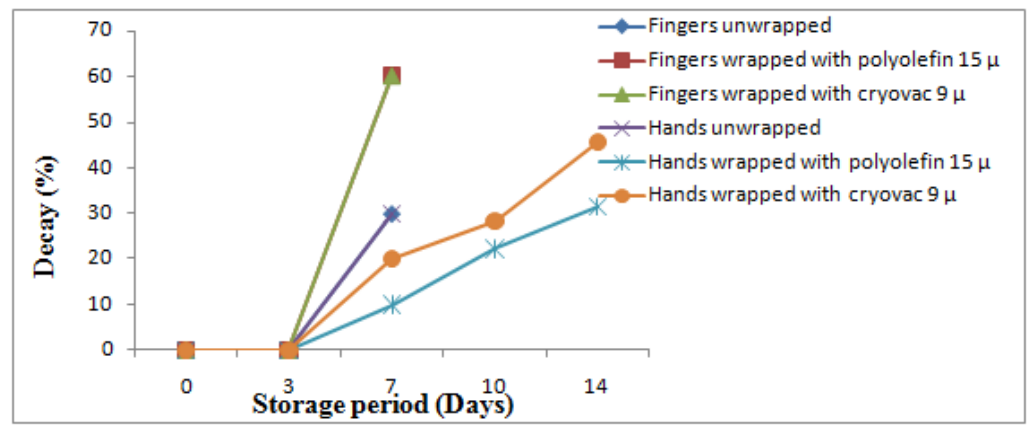

Figure 4: Effect of Heat Shrinkable Films on Decay (\%) of Chakkerkeli Bananas

$\mathrm{CO}_{2}$ transmission rate (\%) increased in all the treatments with the increase in storage period (Figure.5). The highest value was significantly recorded with unwrapped hands and lowest value was found with hands wrapped with polyolefin $15 \mu$. A similar trend was observed by Dhall et al. (2010). Shrink wrapped banana had a lower transmission rate than unwrapped banana with the lowest $\mathrm{CO} 2$ transmission rate in hands wrapped with polyolefin $15 \mu$. The lower transmission rate in shrink wrapped treatments might have delayed ripening by creating modified atmospheric conditions inside the wrapped fruits.

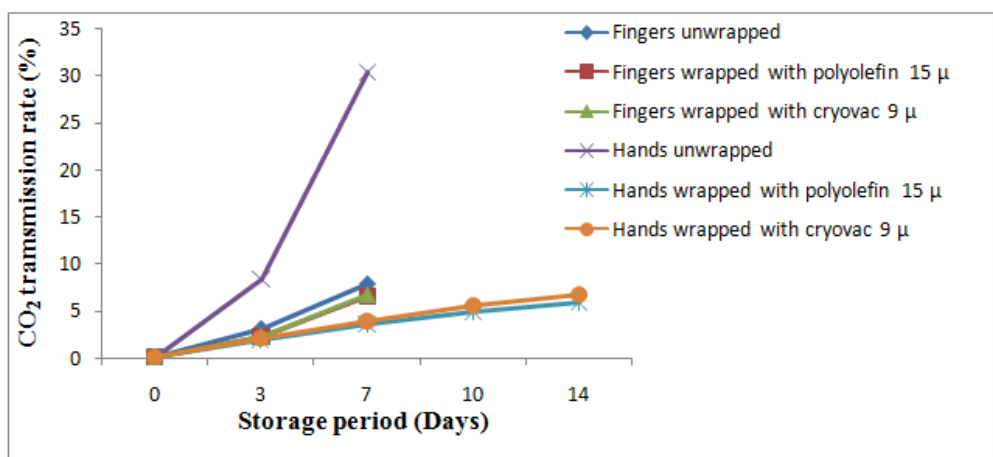

Figure 5: Effect of Heat Shrinkable Films on CO2 Transmission Rate of Chakkerkeli Bananas 


\section{CONCLUSIONS}

The present study envisaged that, hand wrapped with polyolefin $15 \mu$ retained higher values, for most of the physiological parameters studied under ambient storage conditions $\left(72 \% \mathrm{RH}, 33^{\circ} \mathrm{C}\right)$. Heat shrinkable packaging film can prolong the shelf life of Chakkerkeli bananas, up to14 days with acceptable quality.

\section{REFERENCES}

1. Dhall, R. K., Mahajan, B. V. C and Garg, A. 2010. Evaluation of Shrink Wrapping on Shelf Life and Quality of Cucumber during Different Storage Conditions. Acta Horticulture. 877: 403-410.

2. Embaby El-Sayed, M., Hazaa, M., Hagag, F., Talaat El-Sayed Ibrahim and Faten S. Abd El-Azem. 2013. Decay of Some Citrus Fruit Quality Caused by Fungi. Journal of Applied Sciences Research. 9(11): 5920-5929.

3. Nazmy, A. Abd-elghany., Samah, I. Nasr and Hassan, M. Korkar. 2012. Effects of Polyolefin Film Wrapping and Calcium Chloride Treatments on Posthravest Quality of "Wonderful" Pomegranate Fruits. Journal of Horticultural Scienceand Ornamental Plants. 4 (1): 7-17.

4. Rashid Al-Yahyai., Naflaa Al-Waili., Fahad Al Said., Majeed Al-Ani., Annamalai Manickavasagan and Adel Al-Mahdouri. 2012. Effect of storage conditions on physico-chemical attributes and physiological responses of 'milk' (Musa spp., AAB group) banana during fruit ripening. International Journal of PostharvestTechnology and Innovation. 2 (4): 370-386.

5. Sharma, R. R., Pal, R. K and Singh, D. 2010. Storage life and fruit quality of individually shrink wrapped apples (Malus domestica) in zero energy cool chambers. Indian Journal of Agricultural Science. 80 (4): 338-341.

6. Soltani, M., Alimardani1, R and Omid, M. 2011b. Changes in physico-mechanical properties of banana fruit during ripening treatment. Journal of AmericanScience. 7 (5): 14-19.

7. Sreenivasa Murthy, D., Gajanana, T. M., Sudha, M and Dakshinamoorthy, V. 2009. Marketing and Post- Harvest Losses in Fruits: Its Implication on Availability and Economy. Indian Journal of Agricultural Economics. 64(2): 259-274.

8. Tapre, A. R. and Jain, R. K. 2012. Study of advanced maturity stages of banana. International Journal of Advanced Engineering Research and Studies. 1(3): 272-274. 
